OPEN ACCESS

Edited by:

Gastón Moré,

Consejo Nacional de Investigaciones

Científicas y Técnicas (CONICET),

Argentina

Reviewed by:

Quan Liu,

Foshan University, China

Jing liu,

China Agricultural University, China

${ }^{*}$ Correspondence:

Daniela Pontes Chiebao

danielachiebao@biologico.sp.gov.br

Specialty section:

This article was submitted to

Parasitology,

a section of the journa

Frontiers in Veterinary Science

Received: 22 October 2018

Accepted: 06 March 2019

Published: 02 April 2019

Citation:

Chiebao DP, Pena HF, Passarelli D,

Santín T, Pulz LH, Strefezzi RF,

Sevá AP, Martins CM, Lopes EG,

Grisi Filho JHH, Gennari SM and

Soares RM (2019) Congenital

Transmission of Toxoplasma gondii

After Experimental Reinfection With

Brazilian Typical Strains in Chronically

Infected Sheep. Front. Vet. Sci. 6:93.

doi: 10.3389/fvets.2019.00093

\section{Congenital Transmission of Toxoplasma gondii After Experimental Reinfection With Brazilian Typical Strains in Chronically Infected Sheep}

\author{
Daniela Pontes Chiebao ${ }^{1 *}$, Hilda Fátima Pena ${ }^{1}$, Danielle Passarelli ${ }^{2}$, Thiago Santín ${ }^{3}$, \\ Lidia Hildebrand Pulz ${ }^{4}$, Ricardo Francisco Strefezzi ${ }^{2}$, Anaiá Paixão Sevá ${ }^{1}$, \\ Camila Marinelli Martins ${ }^{1}$, Estela Gallucci Lopes ${ }^{1}$, José Henrique Hildebrand Grisi Filho ${ }^{1}$, \\ Solange Maria Gennari ${ }^{1}$ and Rodrigo Martins Soares ${ }^{1}$
}

\footnotetext{
${ }^{1}$ Department of Preventive Veterinary Medicine, Faculty of Veterinary Medicine and Animal Science (FMVZ), University of São Paulo, São Paulo, Brazil, ${ }^{2}$ Department of Veterinary Medicine, Faculty of Animal Science and Food Engineering (FZEA), University of São Paulo, São Paulo, Brazil, ${ }^{3}$ Department of Animal Reproduction, Faculty of Veterinary Medicine and Animal Science (FMVZ), University of São Paulo, São Paulo, Brazil, ${ }^{4}$ Department of Pathology, Faculty of Veterinary Medicine and Animal Science (FMVZ), University of São Paulo, São Paulo, Brazil
}

Toxoplasma gondii is a cause of congenital diseases, miscarriages and stillbirths in production animals. In Brazil, non-archetypal genotypes of the parasite may be related to severe disease. Experimental infection with T. gondii was studied in sheep to analyse congenital transmission-related parameters in reinfections with different Brazilian parasite strains. Thirteen T. gondii-seronegative sheep were orally infected with $2 \times 10^{3}$ oocysts for the primary infection: G1 (4 animals) were inoculated with TgCatBr71 strain (Type $\mathrm{Br}$ genotype) and $\mathrm{G} 2$ andG3 (5 and 4 animals, respectively) withTgCatBr60 strain (Type Brlll genotype). After chronification of infection, the animals were impregnated. A second infection was performed after 60 days of gestation. TheG1 andG3 animals were inoculated withTgCatBr60Brlll and the $\mathrm{G} 2$ animals withTgCatBr71 $\mathrm{Brl}$ oocysts. The effects of reinfection were compared with a control group ( 5 animals) through physical examination, ultrasound imaging and serology. Ovine experimental infections were evaluated using mouse bioassays, molecular analysis, serological tests, histopathology, and immunohistochemistry. No abortions occurred; a seropositive lamb and a mummified fetus from G2-BrlllxBrl were produced. The vertical transmission rate detected in lambs from chronically infected sheep was $31.6 \%(6 / 19)$. It is demonstrated that reinfection and subsequent congenital transmission occured in one sheep with a primary Brl infection challenged with Brlll genotype of $T$. gondii. In a twin pregnancy from G2-BrlllxBrl, congenital transmission from a latent infection was detected in both lambs. Congenital transmission could not be tracked in three lambs. Overall, previous T. gondii infection may fail to protect against congenital transmission from a reinfection and primary infection induced insufficient protection against vertical transmission which must be taken into 
account in decision-making for the use of seropositive animals as breeders. Similar trials with larger groups and contemplating host cellular immune response studies should be conducted to evaluate the actual impact of $T$. gondii reinfection involving different strains in sheep.

Keywords: toxoplasmosis, oocysts, ovine, abortion, vertical transmission

\section{INTRODUCTION}

Toxoplasma gondii is a cosmopolitan protozoan of the Apicomplexa phylum and the aetiological agent of toxoplasmosis. Its definitive hosts are felids (1), although hundreds of animal species, ranging from birds to mammals, including humans, may act as intermediate hosts (2). This parasite is transmitted through three main routes: (1) ingestion of oocysts eliminated in the feces of felids, which become infectious in the environment and contaminate water, soil, and food; (2) consumption of raw or undercooked meat of intermediate hosts containing viable tissue cysts with bradyzoites; and (3) congenital transmission via tachyzoites from the maternal host reaching the placenta and fetus (3).

Because T. gondii causes diseases with varying degrees of severity in its hosts, it is considered an important public and animal health problem and is recognized as the main parasitic cause of abortions in sheep (4). Toxoplasmosis in sheep usually clinically manifests after primary infection of a pregnant female and may lead to fetal death, mummification, abortion, or stillbirth, depending on the gestation stage (5). Although congenital transmission derived from primary infection is considered the most common route (6), transplacental transmission may also occur after recurrence of persistent infection with reactivation of latent cysts in the maternal organism (7).

Early studies with ewes naturally infected and experimentally infected with oocysts have indicated that sheep only experience reproductive problems after the first infection because, once infected, they produce an efficient and long-lasting cellular immune response that prevents the occurrence of congenital transmission or renders this event uncommon $(5,8)$. Studies based on the molecular diagnosis of T. gondii, without its isolation, have suggested that primary infection fails to provide protection against subsequent infections, resulting in a risk of vertical transmission in chronically infected animals $(6,9-$ 11). In Brazil, studies have also indicated that experimental congenital transmission of $T$. gondii commonly occurs during various stages of gestation in chronically infected sheep (12), but these studies did not identify the strain genotype responsible for infection.

Different $T$. gondii variants may have different biological behaviors regarding the mode of transmission, virulence and ability to cause abortions in successive pregnancies in sheep $(10,13) . T$. gondii is a ubiquitous agent with high genotypic diversity and a peculiar population structure. The Type II and Type III clonal archetypes prevail in North American and European populations, whereas the number of prevalent genotypes is much higher in other parts of the world, particularly in South America $(14,15)$. An increased occurrence of the Types BrI, BrII, and BrIII non-archetypal genotypes was reported in sheep in Brazil $(16,17)$, although the archetypal Type II was recently described (18). The various T. gondii genotypes may also lead to different immune responses, as shown in a study in which lamb vaccination against toxoplasmosis, while drastically reduced parasite burden, failed to prevent reinfection when the animals were orally challenged with oocysts from a strain of another genotype (19).

Considering the questions regarding the occurrence of congenital toxoplasmosis transmission in sheep and the vast genotypic diversity of $T$. gondii in Brazil and South America, an experimental study is needed in sheep to analyse these parasite variables, to provide insights into the biological behavior of the variants prevalent in Brazil and to compare the results with data on the widely studied variants (archetypes I, II, and III). This study reports for the first time the outcomes of experimental oral infections of sheep with T. gondii oocysts from two field isolates presenting typical Brazilian genotypes, followed by reinfection of these animals with oocysts with a genotype different from that used in the primary infection. The sheep were impregnated between primary infection and reinfection to assess the effects of reinfection with a strain of a different genotype during pregnancy. Molecular diagnosis was performed to identify the strain of the parasite established after reinfection.

\section{METHODS}

\section{T. gondii Isolates}

The TgCatBr71 (ToxoDB RFLP\#6 or Type BrI) andTgCatBr60 (ToxoDB RFLP\#8 or Type BrIII) isolates were selected for the experimental infection. Although the outcome of the disease may be different among species, these isolates were chosen because they show high genetic divergence and different pathogenicity in mice and occur at high frequencies in Brazil (17, 20-22). Both isolates were obtained by Pena et al. (20) and preserved in liquid nitrogen $\left(-196^{\circ} \mathrm{C}\right)$.

Toxoplasma gondii tachyzoite and bradyzoite thawed saline suspensions were subcutaneously inoculated ( $1 \mathrm{~mL}$ per mice) into 50 female albino Swiss mice ( 25 for each isolate) to obtain chronically infected animals. Tachyzoites from the frozen tissues were not quantified whereas the purpose was reactivation in mice. When a second passage was necessary, the bradyzoite saline suspension contained 10 cists per inoculum. Mice inoculated with the Type BrI isolate were orally treated with sodium sulfadiazine $(125 \mathrm{mg} / 100 \mathrm{~mL})$ in the drinking water from day 0 
post-inoculation (p.i.) to day 21 p.i.to induce the formation of tissue cysts, as Type BrI strains are normally virulent to mice (21).

The mice were kept in cages with five animals each and checked twice a day for signs of illness. Two months p.i., the mice were euthanized, and a small part of their brain cortex was microscopically examined for $T$. gondii cyst presence. Afterwards, 20 mice, 10 of each isolate, were selected for the cat bioassay.

\section{Bioassay in Cats}

A litter of six cats descended from chipped breeders donated from a vaccine company (Laboratory Biovet) were used for the bioassay. After weaning, they tested seronegative for T. gondii (titer $<16$ ) and Neospora caninum (titer $<50$ ) according to the indirect immunofluorescence antibody test (IFAT). The cats were previously de-wormed, vaccinated and kept in individual cages with water ad libitum and commercial dry cat food according to the manufacturer instructions.

Euthanized mice chronically infected with T. gondii (2 months p.i.) were fed to cats aged 3-6 months old. Three cats were designated for each isolate. After $12 \mathrm{~h}$ of fasting, each cat ate at least two positive brains, and then, the whole mouse carcass was offered. Cats inoculated with different isolates were maintained in separate rooms and attended by different keepers four times a day for data and sample collections. Stool samples were examined daily for 30 days p.i.to detect oocysts using a sucrose flotation solution method (23). When identified, oocysts were recovered from the total feces, purified and concentrated for sporulation with $2 \% \mathrm{H}_{2} \mathrm{SO}_{4}$ in an incubator at $25^{\circ} \mathrm{C}$ according to the method described by Dubey (2). The sporulated oocysts of each isolate were kept refrigerated at $4^{\circ} \mathrm{C}$.Prior to use in the experiments, the oocysts were washed and resuspended in antibiotic (penicillin and streptomycin, $2000 \mathrm{IU}$ and $200 \mu \mathrm{g} / \mathrm{mL}$, respectively) and antifungal solutions. The suspension concentration was determined using a Neubauer chamber.

To confirm oocyst viability, 20 Swiss albino mice were divided into two groups of 10 animals each, and each group was orally inoculated with 50 oocysts per mouse with the TgCatBr71Type BrI strain and the other with the TgCatBr60-Type BrIII strain. Animals had lung and liver samples collected to identify tachyzoites in slide imprints and brain material collected to identify tissue cysts in slide smears.

\section{Experimental Infection in Sheep}

Eighteen Santa Inês ewe lambs $\sim 1$ year of age were purchased from a government breeding centre (Animal Science Institute of Nova Odessa/Sao Paulo-Instituto de Zootecnia de Nova Odessa, Sao Paulo State Department of Agriculture and Food SupplySecretaria da Agricultura e Abastecimento do Estado de São Paulo) and quarantined at the experimental site on the USP campus in Pirassununga, São Paulo, Brazil. The animals were enclosed in roofed and fenced concrete pens, fed controlled diets and provided treated tap water. The lambs were immunized with anti-rabies and anti-clostridium vaccines and subjected to strategic parasite control.
Serum was collected for anti-T. gondii, anti-N. caninum, antiBrucella abortus, anti-B. ovis, and anti-Leptospira spp. antibody detection analysis at the beginning and end of the quarantine. A reproductive evaluation (puberty diagnosis, oestrous phase, and uterus and ovary integrity, and size determinations) was performed using ultrasound (US) methods.

The animals were divided into four groups as follows: Group 1, four sheep (Nos. 1, 2, 3, and 4) received experimental primary infections with TgCatBr71-Type BrI oocysts and were then experimentally reinoculated with TgCatBr60-Type BrIII oocysts (G1-BrIxBrIII); Group 2, five sheep (Nos. 5, 6, 7, 8, and 9) received experimental primary infections with TgCatBr60Type BrIII oocysts and were then experimentally reinoculated with TgCatBr71-Type BrI oocysts (G2-BrIIIxBrI); Group 3, four sheep (Nos. 10, 11, 12, and 13) received both experimental primary infection and reinoculation with TgCatBr60-Type BrIII oocysts (G3-BrIIIxBrIII); and Group 4, five sheep belonged to the uninfected control group (CG).

The G1, G2, and G3 sheep were inoculated with 2,000 oocysts per animal using an esophageal probe with the specific inoculum. The five CG animals were treated with physiological saline solution. All sheep were monitored once a day for 15 days p.i. and weekly afterwards to assess clinical parameters (rectal temperature, heart and respiratory rates, and lymph node status). Animals received proper treatment in the case of fever, pain, dehydration, and other common ovine affections, such as hoof disorders and caseous lymphadenitis. Serum was collected weekly until the second experimental infection was performed.

Four months after primary infection, all sheep were impregnated by natural mating using two T. gondii-, $N$. caninum-, B. abortus- , and B. ovis-seronegative Santa Inês rams evaluated under quarantine as described above. Oestrus was synchronized using controlled internal drug release $\left(\mathrm{CIDR}^{\circledR}\right)$ intravaginal implants and estrogen and progesterone intramuscular applications (24). Pregnancy was confirmed by US 21 days after the mating period. In cases of oestrus detection, the same protocol was performed until the female became pregnant.

At 60 days of gestation, the G1, G2, and G3 sheep were subjected to a second experimental inoculation by esophageal probe with 2,000 T. gondii oocysts of the specific inoculum. The time of the second inoculation was chosen because the fetal heart rate can be measured by US at this age and this period has the highest incidence of abortions caused by T. gondii (25). The CG sheep were treated with physiological saline solution. The rectal temperature was assessed daily for 30 days p.i. and the other vital parameters as before. Serum collection and US (for fetal viability) were performed weekly for 15 weeks, until completion of the experiment.

Lambs were separated from their mothers after birth without ingesting the colostrum and were euthanized by jugular intravenous injection of veterinary euthanasia medication (T61 ${ }^{\circledR}$, MSD Animal Health, $4 \mathrm{~mL} / 50 \mathrm{~kg}$ ). The time point of the lamb sacrifice was chosen to minimize stress for the sheep and personnel, avoid unnecessary suffering and prevent stillborn losses. Adult sheep from all groups were euthanized after delivery by sanitary slaughtering at the school slaughterhouse on the USP campus in Pirassununga, São Paulo. 


\section{Serological Tests}

IFAT was performed for the anti-T. gondii and anti-N. caninum antibody analysis using 64 and $50 \mathrm{~T}$. gondii antibody titres as the cut-off points for the adult sheep, respectively, and 16 as the cut-off point for the mice $(26,27)$. The $T$. gondii cut-off point used for the lambs was 4. Cell culture tachyzoites derived from the RH strain of T. gondii and the NC-1 strain of N. caninum were used as the antigens. Serodiagnosis for anti-B. abortus antibody detection in adult sheep was performed using the Rose Bengal-stained rapid plate seroagglutination with buffered acidified antigen (BAA) test (28). The agar gel immunodiffusion test using a commercial antigen was performed for $B$. ovis according to the manufacturer's instructions (Tecpar, Curitiba, Brazil). Adult sheep sera were also tested using the microscopic seroagglutination (MSA) micro-technique with live antigens (29) to test for antibodies against an antigenic battery of 22 Leptospira spp. serovars.

\section{Sheep Sample Collection After Infection}

Prior to euthanasia, blood samples were collected from all animals to obtain serum. Following sheep and lamb euthanasia, the animals were inspected to identify any macroscopic alterations, and the tissues were collected aseptically. Sheep brain, heart, masseter, diaphragm, and semimembranosus and semitendinosus muscle samples were collected and pooled for the mouse bioassay. Parts of the brain, heart, liver, semimembranosus and semitendinosus muscle, placenta, and uterus samples were separated for the molecular and histopathological tests. The lamb brain, heart, and semimembranosus and semitendinosus muscle samples were separated and pooled for the mouse bioassay. Brain, heart, liver, and submandibular, popliteal and mesenteric lymph node samples were collected for the molecular and histopathological tests.

\section{Histopathology and Immunohistochemistry}

The tissue fragments described before were fixed in $10 \%$ formalin buffered with phosphate buffer solution $\left(0.05 \mathrm{M} \mathrm{NaH}_{2} \mathrm{PO}_{4}, \mathrm{pH}\right.$ $7.2-7.4$ ) for $24 \mathrm{~h}$ at a $1: 10$ ratio and then transferred into $70 \%$ ethanol. The tissues were dehydrated, diaphanized, impregnated, cut into $4-\mu \mathrm{m}$-thick sections and stained using the haematoxylin and eosin (HE) method (30). Lesions observed, comparing with negative tissue slides, were described. Special staining by periodic acid-Schiff (PAS) reaction was performed to help identify the bradyzoites.

The method adapted from Atmaca et al. (31) was used to perform immunohistochemistry (IHC). After antigen recovery from the slides (sodium citrate buffer, $\mathrm{pH} 6.0,2$ min under pressure), the slides were immersed in $3 \% \mathrm{H}_{2} \mathrm{O}_{2}$ for $30 \mathrm{~min}$ and in 5\% skim milk for $30 \mathrm{~min}$. A rabbit anti-Toxoplasma polyclonal antibody (Abcam, Cambridge, USA) at a 1:200 dilution (Code AB15170) and a kit consisting of labeled streptavidin biotin reagents (Dako LSAB ${ }^{\circledR} 2$ System-HRP, Dako Cytomation, Carpinteria, CA, USA) including a biotinylated anti-rabbit and anti-mouse immunoglobulins and streptavidin conjugated to horseradish peroxidase (Code K0609) were used according to the manufacturer's instructions to demonstrate $T$. gondii antigens in the slides. The histological sections on the slides were counterstained with Harris haematoxylin, followed by washes, dehydration, and diaphanization for mounting in synthetic resin on a cover slip. Mice tissues from the oocysts viability test were used as a positive control. Negative-control (N) slides were incubated using the same protocol with rabbit IgG and processed simultaneously to rule out non-specific interactions. The interpretation of positive results was based in immunohistochemically labeled antigen visualization.

\section{Mouse Bioassay}

For T. gondii isolation, a protocol previously described was followed (32). Briefly, a pool of $50 \mathrm{~g}$ of tissues from each sheep and lamb was digested separately in pepsin acid solution, the suspensions were filtered, centrifuged and neutralized with $1.2 \% \mathrm{NaHCO}_{3}$ (pH 8.3), and the pellets were resuspended in antibiotics. Each suspension was used as a subcutaneous inoculum in groups of four 60-day-old albino Swiss mice (1 $\mathrm{mL} /$ animal) per ovine. In the case of twin gestation, a pool of organs from both lambs (L1 and L2) was prepared for a group of four mice. The groups of mice were kept in separate cages and observed daily, and the procedures were performed as described above. The surviving animals were euthanized 60 days p.i. Mouse heart and brain samples were collected and stored at $-20^{\circ} \mathrm{C}$ for molecular analysis, and plasma was collected from the thoracic cavity for anti- $T$. gondii antibody detection by IFAT.

\section{Molecular Diagnosis of T. gondii}

DNA was extracted from the sheep and mouse tissues using a DNeasy Blood and Tissue kit (Qiagen ${ }^{\circledR}$ Inc., USA). The Tissue Spin and Blood Spin protocols were followed according to the manufacturer's recommendations. Internal transcribed spacer 1 (ITS-1) sequences of Toxoplasmatidae were identified by polymerase chain reaction (PCR-ITS1) as previously described (33-35). Positive (RH strain tachyzoite DNA) and negative (ultrapure water) controls were included in each reaction. The amplified products were resolved by $2 \%$ agarose gel electrophoresis and stained with ethidium bromide.

Nested polymerase chain reaction-restriction fragment length polymorphism (nested PCR-RFLP) directed at the T. gondii ß-tubulin (BTUB) gene was also performed to differentiate BrI from BrIII sequences $(21,36)$. Reference samples for different genotypes were used as positive controls (RH, PTG, CTG, Cougar, MAS, and TgCatBr5 strain tachyzoite DNA) and ultrapure water as a reaction negative control. The amplified and restriction-digested products were resolved by $2.5 \%$ agarose gel electrophoresis and stained with SYBR ${ }^{\circledR}$ Safe DNA Gel Stain (Invitrogen, USA).

\section{Statistical Analysis}

The area under the mean antibody titer curve was calculated for each group, and the results were assessed by two-way analysis of variance (ANOVA) to compare humoral response data between groups. Tests were considered significant when $P<0.05$ using Statistical Package for the Social Sciences (SPSS) software, version 16 (SPSS Inc., SPSS for Windows, Chicago, IL, USA). 


\section{RESULTS}

\section{T. gondii Inoculum Viability}

All cats remained healthy, and none was observed with diarrhea or fever during the bioassay. Approximately $2.0 \times 10^{6}$ sporulated oocysts were obtained from the TgCatBr71 Type BrI isolate, and $1.2 \times 10^{7}$ oocysts were obtained from the TgCatBr60 Type BrIII isolate. Nine of the ten mice inoculated with the BrI genotype oocysts showed signs of acute toxoplasmosis between 9 and 13 days p.i., with tachyzoites detected in the lungs. These mice either suddenly died (eight cases) of acute disease or were euthanized as soon as unambiguously clinical sign compatible to acute toxoplasmosis was noticed (1 case). The tenth mouse did not show any clinical sign and was euthanized 35 days p.i. It was positive only in the serological examination by IFAT. The 10 mice inoculated with BrIII genotype oocysts showed clinical signs of disease (ruffled fur, arched back, and dehydration). Tissue cysts were observed in all these mouse brains. Thus, oocysts of both isolates were viable for sheep inoculation.

\section{Clinical Signs in Sheep}

Sheep from the experimental groups showed hyperthermia (Figure 1), hyporexia and apathy on days 7 to 9 after primary infection. No further changes in vital signs were detected throughout the remainder of the experiment. No abortions were observed during the study (Supplementary Material). The animals from all groups had full-term gestations according to the weekly US. A total of 24 lambs were born from the 18 impregnated sheep, including 19 from the 13 experimentally infected sheep. Sheep 5 (G2-BrIII x BrI) delivered a live lamb, and a $30-\mathrm{cm}$-long mummified fetus was expelled with the placental expulsion. Excluding the mummified fetus, all of the lambs were born healthy and without notable congenital deformities based on visual inspection. Ewes from G1, G2, and G3 produced 6, 8, and 5 lambs, respectively. A disseminated inflammatory reaction like fibrinoid deposit was observed in the placentas of all sheep from the three experimental groups, whereas the placentas of the CG animals showed no alterations.

In addition to the above findings, the presence of $T$. gondii DNA was detected in the placenta of sheep 11 (G3-BrIII x BrIII), and the BrIII genotype of the isolate was confirmed by PCRRFLP. Pathology analysis by HE showed mononuclear infiltrate and antigen label by IHC was confirmed in the placentas of sheep 3 (G1-BrIxBrIII), sheep 6 (G2-BrIIIxBrI), and sheep 13 (G3BrIIIxBrIII), although no signs of congenital transmission were observed in any of these animals.

\section{IgG Anti-T. gondii Antibody Serology}

Two weeks after the primary infection, all 13 sheep from the experimental groups had anti- $T$. gondii antibody titres $\geq 64$, with a peak up to 32,768 at 6 weeks p.i. and an antibody titer decline after 12 weeks p.i. These animals remained seropositive until the second infection. All CG sheep and offspring remained negative in the IFAT for T. gondii (titer <64). Lamb 2 of sheep 7 (G2-BrIII $\mathrm{x} \mathrm{BrI}$ ) was seropositive in the IFAT (titer $=64$ ).

Figure 2 shows the mean humoural response kinetics in the experimental groups throughout the experiment. No intergroup differences in the mean antibody titres were detected in the first or second infection. However, when the intragroup mean titer variation throughout the experiment was tested, a difference between the first and second infections $(P=0.016)$ was observed in G1-BrI x BrIII, with mean titres significantly lower in the second infection compared with the first infection.

\section{Necropsy Data}

Generalized lymphadenomegaly was observed in lamb 1 of sheep 1 (G1-BrIxBrIII), both lambs of sheep 7 and lamb 1 of sheep 8 (G2-BrIIIxBrI). One lamb of sheep 7 also had splenomegaly. The only offspring of sheep 10 (G3-BrIIIxBrIII) had enlarged popliteal lymph nodes and hepatomegaly. Hepatomegaly was the only finding in lamb 2 of sheep 11 (G3-BrIIIxBrIII).

\section{Sheep Infection With T. gondii}

Brain samples from all 13 experimentally infected sheep were positive by PCR-ITS1. T. gondii was isolated from 10 animals; the exceptions were sheep 6,8, and 9. All mice inoculated with tissues from the 13 sheep were IFAT positive (Table 1). Acute toxoplasmosis occurred in mice inoculated with tissues from sheep 2, 3, and 4 (G1-BrI x BrIII) (7/12) and from sheep 13 (G3-BrIII x BrIII) (1/4). No mouse inoculated with tissues from sheep 1 (G1-BrIxBrIII) became sick or died, but tissue cysts were observed in their brains. In all sheep in which different isolates were used (G1 and G2), the strain genotype obtained in the mouse bioassays corresponded to the isolate used in the primary infection except for sheep 1 (G1-BrI x BrIII) (Table 1) which is evidence of reinfection. In sheep 6, 8, and 9 (G2-BrIIIxBrI), genotyping was performed using DNA directly obtained from the sheep brain by PCR-RFLP. Genotyping was only successful for sheep 9, in which the Type BrIII genotype was obtained.

\section{Lamb Infections With T. gondii}

Vertical transmission was confirmed in six lambs of the 19 offspring obtained $(31.6 \%)$. Vertical transmission was defined if $T$. gondii was detect in fetuses by HE/IHC and/or PCRRFLP and/or mouse isolation. Considering the total number of pregnancies, congenital transmission occurred in five of 13 (35.5\%). Infection with T. gondii was confirmed in lambs born of sheep 1 (G1-BrI x BrIII); 7 (L1 and L2) and 9 (G2-BrIII x $\mathrm{BrI})$; and 10 and 11 (G3-BrIII x BrIII). The rate transmission in G1 was the lowest, $16.7 \%$ (1/6), followed by G2 with $37.5 \%$ (3/8) and the highest in G3 in which two out of five lambs were congenitally infected (40\%). Results from the analysis of tissues of confirmed T. gondii-infected lambs are outlined in Table 2 and Figure 3. For sheep 1 (G1-BrI x BrIII), the strain genotype involved in the infection of L1 was BrIII, indicating the occurrence of transplacental transmission from a second oocyst infection. Histopathology analysis revealed small loci of mononuclear inflammatory infiltrate in the liver parenchyma of lamb 1. For sheep 7 (G2-BrIII x BrI), genotyping showed that congenital transmission for L1 and L2 was caused by the TgCatBr60-Type BrIII strain and was therefore a reactivation of a latent BrIII infection. A few loci of necrosis and mononuclear inflammatory infiltrate was found in the liver of lamb 1 from 


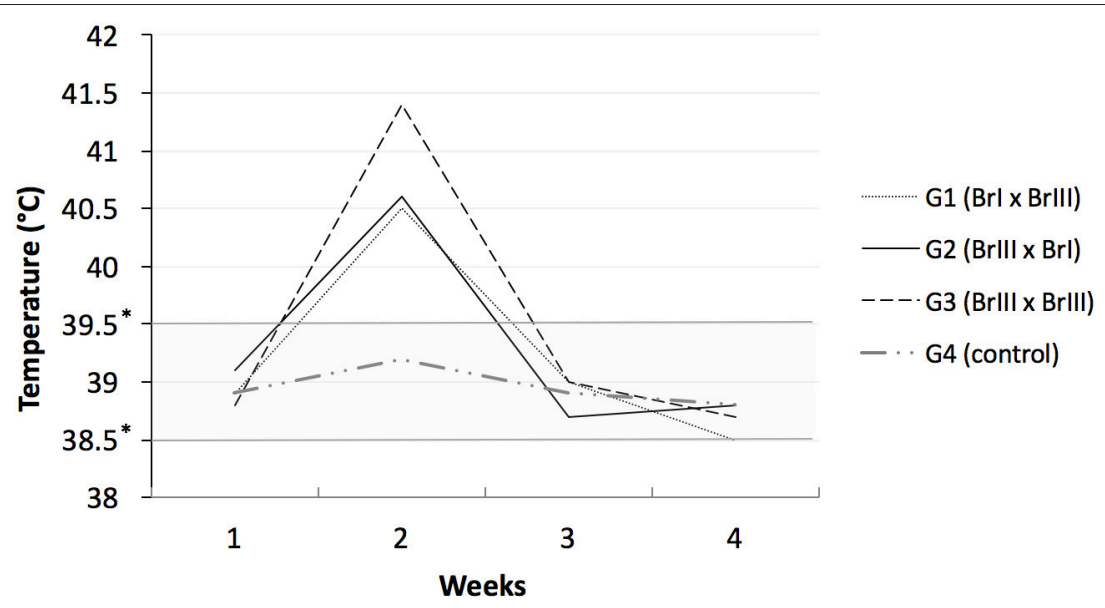

FIGURE 1 | Sheep rectal temperatures after experimental prime infection using oocysts of Toxoplamsa gondii isolates TgCatBr71 (genotype Brl or TOXODB\#6) and TgCatBr60 (genotype Brlll or TOXODB\#8) *low and high limits of normal temperatures.

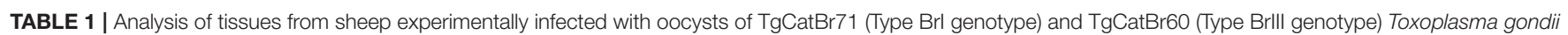
isolates after a second infection following the chronification of a primary infection.

\begin{tabular}{|c|c|c|c|c|c|}
\hline \multirow[t]{2}{*}{ Group } & \multirow{2}{*}{$\begin{array}{l}\text { Sheep } \\
\text { number }\end{array}$} & \multirow{2}{*}{$\begin{array}{l}\text { PCR-ITS1 from primary } \\
\text { sample (brain) }\end{array}$} & \multicolumn{2}{|c|}{ Isolation from mouse bioassays } & \multirow{2}{*}{$\begin{array}{l}\text { Isolates genotype } \\
\text { (PCR-RFLP)/Mouse serology } \\
\text { (IFAT titer }>64)\end{array}$} \\
\hline & & & $\begin{array}{l}\text { Tachyzoites } \\
\text { (lungs) 16-26 } \\
\text { days p.i. }\end{array}$ & $\begin{array}{l}\text { Cysts (brain) } 60 \\
\text { days p.i. }\end{array}$ & \\
\hline \multirow[t]{4}{*}{ G1-BrlxBrlll } & 1 & Positive & $\mathrm{N}$ & Positive & Brlll/Positive \\
\hline & 2 & Positive & Positive & $\mathrm{N}$ & Brl/Positive \\
\hline & 3 & Positive & Positive & $\mathrm{N}$ & Brl/Positive \\
\hline & 4 & Positive & Positive & $\mathrm{N}$ & Brl/Positive \\
\hline \multirow[t]{5}{*}{ G2-BrlllxBrl } & 5 & Positive & $N$ & Positive & Brlll/Positive \\
\hline & 6 & Positive & $\mathrm{N}$ & $\mathrm{N}$ & ND/Positive \\
\hline & 7 & Positive & $\mathrm{N}$ & Positive & Brlll/Positive \\
\hline & 8 & Positive & $\mathrm{N}$ & $\mathrm{N}$ & ND/Positive \\
\hline & 9 & Positive & $N$ & $\mathrm{~N}$ & Brlll/Positive \\
\hline \multirow[t]{4}{*}{ G3-BrlllxBrlll } & 10 & Positive & $N$ & Positive & Brlll/Positive \\
\hline & 11 & Positive* & $N$ & Positive & Brlll/Positive \\
\hline & 12 & Positive & $N$ & Positive & Brlll/Positive \\
\hline & 13 & Positive $^{\star \star}$ & Positive & Positive & Brlll/Positive \\
\hline
\end{tabular}

$N D$, not done; *also placenta; **also heart; N, negative.

sheep 7 (G2). Congestive lesions were detected in the heart from lamb of sheep 10 from G3.

Analysis of the mummified fetus tissues were tried by PCR and HE/IHC but resulted negative probably due to sample decomposition.

\section{DISCUSSION}

Outbreaks of toxoplasmosis in sheep flocks may lead to extensive economic losses in both Brazil [e.g., in a farm in the state of Rio
Grande do Sul wherein abortions occurred in 58.3\% of the sheep (37)] and other countries [e.g., in the USA wherein a farm in the state of Texas experienced $78 \%$ reproductive losses due to abortions, mummified fetuses or peripartum deaths in 2005 (38)]. Determining the origin of congenital transmission (either from oocyst or from a latent infection) in these reports of outbreaks in farms was not possible. In our study investigating chronically infected sheep, the occurrence of the transplacental transmission derived from a primary infection was only shown in one animal of three infected offspring that could have the genotype assessed. The total percentage of vertical transmission in this study was 


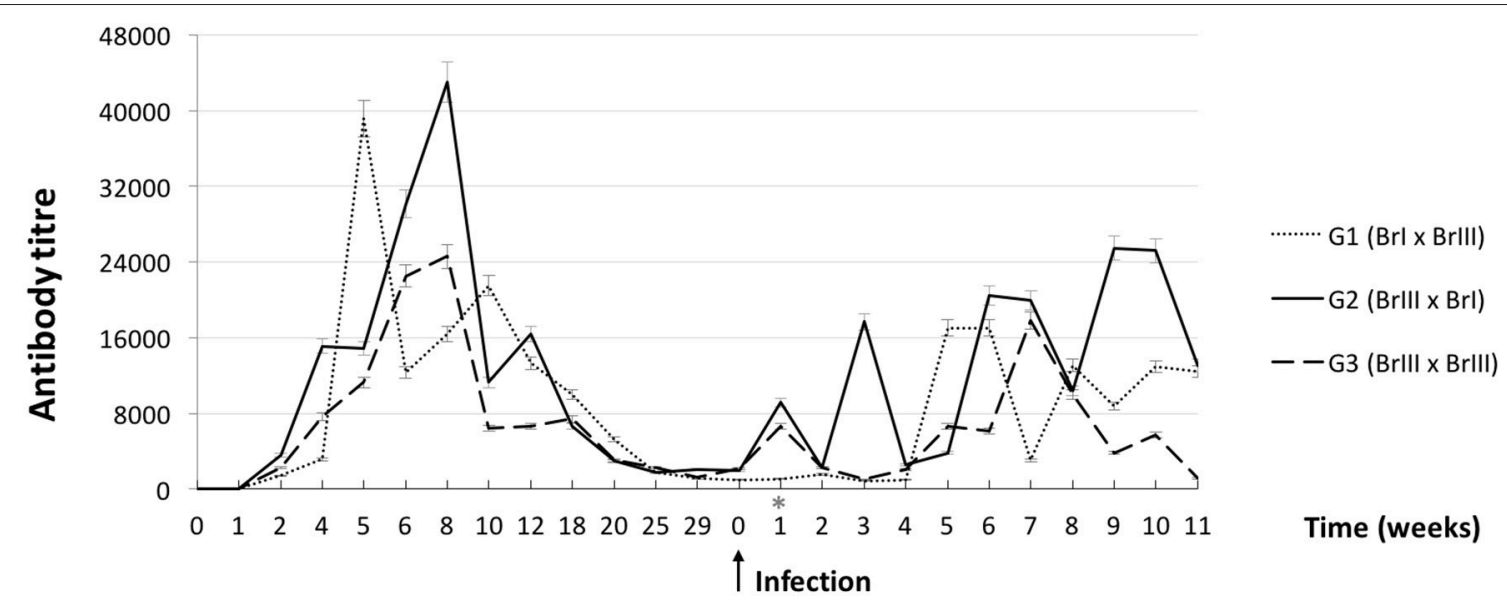

FIGURE 2 | Curves of average anti-Toxoplasma gondii antibody titres from sheep after experimental prime infection using oocysts of the isolates TgCatBr71 (genotype Brl or TOXODB\#6) and TgCatBr60 (genotype Brlll or TOXODB\#8) followed by a second experimental infection during pregnancy (arrow) using oocysts from the same or from a different genotype, showing statistical significance (*) on group 1 (Brl $\times$ Brlll).

TABLE 2 | Results from analysis of tissues of Toxoplasma gondii infected lambs born by sheep with chronic toxoplasmosis after experimental infection using oocysts of $\mathrm{TgCatBr71}$ (Type Brl genotype) and TgCatBr60 (Type Brlll genotype) isolates during pregnancy.

\begin{tabular}{|c|c|c|c|c|c|c|c|}
\hline \multirow[t]{2}{*}{ Sheep group } & \multirow[t]{2}{*}{ Lamb (L) } & \multirow[t]{2}{*}{ IFAT* $^{\star}$} & \multirow[t]{2}{*}{ HE/IHQ (tissue) } & \multirow{2}{*}{$\begin{array}{l}\text { PCR-RFLP genotype } \\
\text { (tissue) }\end{array}$} & \multicolumn{3}{|c|}{ Isolation from mouse bioassays } \\
\hline & & & & & Tachyzoites/cysts & $\begin{array}{l}\text { PCR-RFLP } \\
\text { genotype }\end{array}$ & IFAT $^{\star *}$ \\
\hline G1-BrlxBrlll & L1, Sheep 1 & $\mathrm{~N}$ & Positive (lymph node) & Brlll (lymph node) & $\mathrm{N}$ & ND & $\mathrm{N}$ \\
\hline G2-BrlllxBrl & L1, Sheep 7 & $\mathrm{~N}$ & Positive (lymph node) & Brlll (lymph node) & Positive & Brlll & Positive \\
\hline \multirow[t]{2}{*}{ G3-BrlllxBrlll } & L, Sheep 10 & $\mathrm{~N}$ & $\begin{array}{l}\text { Positive (brain, heart, } \\
\text { lymph node) }\end{array}$ & NS & $\mathrm{N}$ & NS & $\mathrm{N}$ \\
\hline & L1, Sheep 11 & $\mathrm{~N}$ & Positive (lymph node) & Brlll (lymph node) & $\mathrm{N}$ & NS & $\mathrm{N}$ \\
\hline
\end{tabular}

\#L1 and L2 refer to twins; ND, not done; ${ }^{*}$ Cut-off $=1: 4 ;{ }^{*}$ Cut off $=1: 64 ; N$, negative; NS, not successful.

lower than the percentage observed in outbreaks however, in general, the T. gondii infection status of sheep (primary infection or chronic infection) is unknown.

Compared with other vertical transmission studies based on diagnosis by PCR, which indicated rates higher than $60 \%$ in sheep without a defined history of toxoplasmosis $(9,39)$ or up to $48 \%$ in families of Charollais sheep with natural chronic infections (40), the results reported herein showed a lower rate of transmission that did not result in abortions or neonatal deformities, with the exception of one mummified fetus. Because these outcomes are the main characteristics related to economic losses resulting from disease in sheep flocks, the present study suggests that congenital transmission in chronically infected animals has no greater impact than transmission by ingestion of $T$. gondii oocysts from a contaminated environment, which was previously established $(7,41)$ as a source of infection for sheep that adversely affects the reproductive performance of sheep flocks. As $68 \%$ of the lambs (13/19) produced in this study were not infected, we concluded that the primary infection induces moderate protection against vertical transmission. In fact, this transmission route is considered non-negligible $(7,41)$ and should be considered in toxoplasmosis control programmes. It was stablished that two out of three infected lambs experienced transmission derived from reactivation of a latent infection what must have resulted from reactivation of the primary infection. Although the lambs were born clinically normal and almost all lacked anti-T. gondii antibodies, some tissue alterations were observed, primarily in the lymph nodes and liver (i.e., organs related to the immune response); these findings were corroborated by positive histological and PCR findings. Therefore, these animals could help maintain the life cycle of the parasite and possibly threaten human health. Additionally, as observed in humans (42-45), disease exacerbation could occur during lamb growth, and clinical signs might appear. In the present experiment no sheep had aborted after a second infection, although in six fetuses (from five sheep) we 


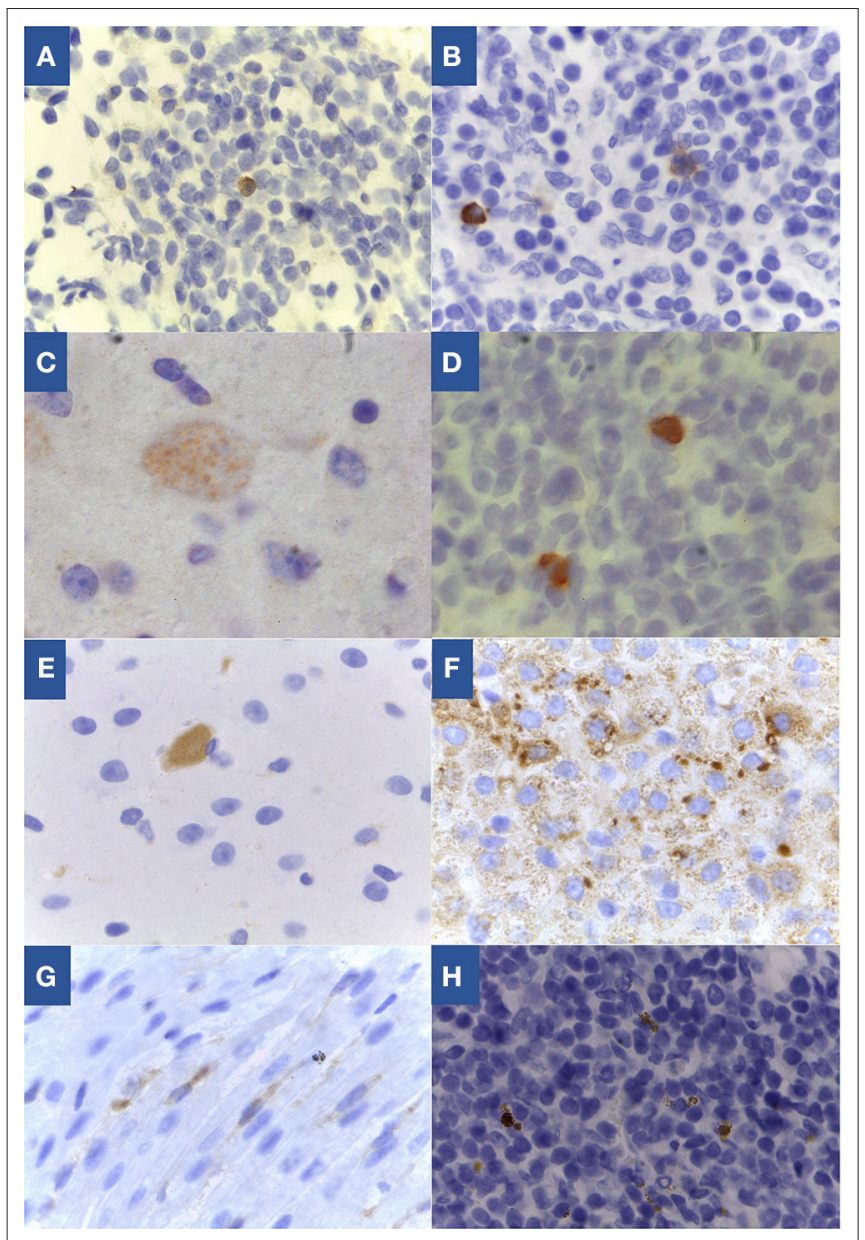

FIGURE 3 | Toxoplasma gondii specific labeling by immunohistochemistry in tissues of congenitally infected lambs. (A) Lymph node from lamb 1 of sheep 1 from G1, 100x; (B) Lymph node from lamb 1 of sheep 7 from G2, 100x; (C) Brain from lamb of sheep 9 from G2, 100x; (D) Lymph node from lamb of sheep 9 from G2, 100x; (E) Brain from lamb of sheep 10 from G3, 100x; (F) Lymph node from lamb of sheep 10 from G3, 40x; (G) Heart from lamb of sheep 10 from G3, 100x; (H) Lymph node from lamb 1 of sheep 11 from G3, 100x.

had collected evidence of $T$. gondii transmission. To know why the six vertical transmissions detected in this study did not result in miscarriages, it would be necessary to evaluate the cellular immune response of the sheep throughout the experiment, comparing with experimentally groups of sheep infected only once.

The gestation period in which the infection occurs may contribute to different results. In our experiment, we estimated that at the time of reinfection the sheep were at a stage where vertical transmission would have a high chance of causing abortion. A study using laboratory reference strains (ME49 and VEG) for experimental infection and reinfection at various gestation stages of Santa Inês sheep reported a high occurrence of congenital transmission and clinical signs in fetuses (12). Evaluating transmission at different time points (40, 80, and 120 days), no abortions were reported in the study, and only one macerated fetus (from the group reinfected at 120 days of gestation) and one mummified fetus (from the group reinfected at 40 days of gestation) were found of the 25 lambs obtained. These data are similar to the findings reported herein. In addition to the gestational time, the higher vertical transmission rate and congenital alterations may be related to the use of parasites with several laboratory passages, which may lead to increased agent virulence.

The higher pathogenicity of the Brazilian strains used in the present study might explain the reinfection on sheep 1 from G1 and further transmission of the second inoculum to the fetus. A study on congenital toxoplasmosis in pregnant rodents of the Calomys genus chronically infected and reinfected with BrI and BrII T. gondii strain genotypes showed that the immune response acquired during primary infection was insufficient to prevent vertical transmission of the challenging strain (46). As observed in the present study, congenital transmission from a latent infection occurred after challenge with the BrI genotype on G2. The pathogenicity of T. gondii infection appears to be dependent on the up and down-regulation of several genes involved in host immune systems (47-49) and this intricate process of regulating gene expression can be altered during reinfection so that future studies are welcome to investigate whether the BrI genotype parasite (pathogenic in mice) might modulate the host immune response during reinfection, thereby enabling the congenital transmission of the BrIII T. gondii strain genotype. In addition, this response may vary according to the host. For example, intestinal immunity might suffice to limit infection with the parasite in pigs vaccinated with $T$. gondii subunits (50). In humans, the parasite genotype may affect the occurrence of congenital toxoplasmosis (51). A cohort study in children from Brazil and Europe showed that toxoplasmic retinochoroiditis is more severe in Brazil, probably owing to the more virulent strains of the parasite (52).

The present study showed that primary infection with the BrI strain genotype might be insufficient to establish a long-lasting immune response because G1-BrIxBrIII showed significant differences in the antibody titres produced by sheep upon reinfection without the expected boosting (53), which might have contributed to sheep reinfection with a parasite of a different genotype.

Histopathological findings in new-born lamb tissues were observed at a lower intensity and in lower numbers than reports from previous studies with primary infections in pregnant ewes (54) and animals vaccinated and challenged with a different T. gondii genotype (19). This finding held true even with the high inoculum dose used in this study, with the exception of the hepatic alterations described in one G2-BrIII x BrI lamb. We hypothesized that primary infection with non-archetypal T. gondii parasites might be more effective in reducing clinical symptoms because challenged sheep from the experimental groups showed no abortions. In mice chronically infected with a genotype BrIII strain, it was observed diminished parasite spread and mortality after oral challenge with $T$. gondii cysts from non-archetypal virulent strains (55). Vertical transmission was lowest in G1 where only one lamb out of 6 was positive which is interesting for future vaccine study since the ewes 
received primary infections with oocysts of genotype BrI, and this variant is phylogenetically and biologically (based on the pathogenicity in mice) close to the type I archetype of the strain used in the commercial vaccine against toxoplasmosis in sheep.

\section{CONCLUSIONS}

The evidence shows that previous T. gondii infection may fail to protect against congenital transmission from a reinfection. Although the congenital infection did not appear to have caused any reproductive loss and were not able to kill the fetuses, the in utero infected lambs were not followed, and the productive and reproductive prognosis of these animals was unknown. Overall, primary infection induced insufficient protection against vertical transmission which must be taken into account in decision-making for the use of seropositive animals as breeders. Similar trials with larger groups and contemplating host cellular immune response studies should be conducted to evaluate the actual impact of $T$. gondii reinfection on production animals.

\section{DATA AVAILABILITY}

All datasets generated for this study are included in the manuscript and/or the Supplementary Files.

\section{ETHICS STATEMENT}

All procedures performed in studies involving animals were in accordance with the Ethical Principles in Animal Research adopted by the College of Animal Experimentation (COBEA) and were approved (protocol number 2351/2011) by the Ethical Committee for Animal Welfare (CEUA), USP, São Paulo.

\section{REFERENCES}

1. Dubey JP, Frenkel JK. Cyst-induced toxoplasmosis in cats. J Protozool. (1972) 19:155-77. doi: 10.1111/j.1550-7408.1972.tb03431.x

2. Dubey JP. Toxoplasmosis of Animals and Humans, 2nd ed. Boca Raton: CRC Press (2010). 336 p.

3. Dubey JP. History of the discovery of the life cycle of Toxoplasma gondii. Int J Parasitol. (2009) 39:877-82. doi: 10.1016/j.ijpara.2009.01.005

4. Dubey JP. Toxoplasmosis in sheep-The last 20 years. Vet Parasitol. (2009) 163:1-14. doi: 10.1016/j.vetpar.2009.02.026

5. Buxton D, Rodger SM, Maley SW, Wright SE. Toxoplasmosis: the possibility of vertical transmission. Small Rumin Res. (2006) 62:43-6. doi: 10.1016/j.smallrumres.2005.07.037

6. Trees AJ, Williams DJL. Endogenous and exogenous transplacental infection in Neospora caninum and Toxoplasma gondii. Trends Parasitol. (2005) 21:55861. doi: 10.1016/j.pt.2005.09.005

7. Innes E a, Bartley PM, Buxton D, Katzer F. Ovine toxoplasmosis. Parasitology. (2009) 136:1887-94. doi: 10.1017/S0031182009991636

8. McColgan C, Buxton D, Blewett DA. Titration of Toxoplasma gondii oocysts in non-pregnant sheep and the effects of subsequent challenge during pregnancy. Vet Rec. (1988) 123:467-70. doi: 10.1136/vr.123.18.467

9. Duncanson P, Terry RS, Smith JE, Hide G. High levels of congenital transmission of Toxoplasma gondii in a comercial sheep flock. Int J Parasitol. (2001) 31:1699-703. doi: 10.1016/S0020-7519(01)00282-X

\section{AUTHOR CONTRIBUTIONS}

DPC, SMG, and RMS conceived and designed the experiment. DPC conducted the experiment. EGL completed the mice bioassay. DP completed the serology. TS completed the sheep clinical and reproductive examinations. HFJP completed the molecular analysis. LHP and RFS completed the histopathological analysis. JHHG, APS, and CMM completed the statistical analysis. DPC, HFJP, RFS, APS, CMM, JHHG, and RMS contributed to the interpretation of data. DPC and RMS wrote the paper. We confirm that the manuscript has been read and approved by all named authors and that there are no other persons who satisfied the criteria for authorship but are not listed. We further confirm that all of us have approved the order of authors listed in the manuscript.

\section{ACKNOWLEDGMENTS}

This study was funded by FAPESP (Research Support Foundation of the State of São Paulo) via a grant to RMS (process number 2011/19297-8). RMS and SMG received grants from CNPq (Brazilian National Council for Scientific and Technological Development). A department grant from CAPES/PROEX (2327/2015) also supported this study. We thank MSc. Mayra Pereira Rocca and Dr. Eduardo Marques for helping with sheep sampling and MSc. Leonardo Batissaco for presenting an oestrus synchronization protocol.

\section{SUPPLEMENTARY MATERIAL}

The Supplementary Material for this article can be found online at: https://www.frontiersin.org/articles/10.3389/fvets. 2019.00093/full\#supplementary-material

10. Morley EK, Williams RH, Hughes JM, Thomasson D, Terry RS, Duncanson $\mathrm{P}$, et al. Evidence that primary infection of Charollais sheep with Toxoplasma gondii may not prevent foetal infection and abortion in subsequent lambings. Parasitology. (2008) 135:169-73. doi: 10.1017/S003118200 7003721

11. Hide G, Morley EK, Hughes JM, Gerwash O, Elmahaishi MS, Elmahaishi KH, et al. Evidence for high levels of vertical transmission in Toxoplasma gondii. Parasitology. (2009) 136:1877-85. doi: 10.1017/S0031182009990941

12. Dos Santos TR, Faria G da SM, Guerreiro BM, dal Pietro NHP da S, Lopes WDZ, da Silva HM, et al. Congenital toxoplasmosis in chronically infected and subsequently challenged ewes. PLoS ONE. (2016) 11:e0165124. doi: 10.1371/journal.pone.0165124

13. Boothroyd JC, Grigg ME. Population biology of Toxoplasma gondii and its relevance to human infection: do different strains cause different disease? Curr Opin Microbiol. (2002) 5:438-42. doi: 10.1016/S1369-5274(02)0 0349-1

14. Khan A, Fux B, Su C, Dubey JP, Darde ML, Ajioka JW, et al. Recent transcontinental sweep of Toxoplasma gondii driven by a single monomorphic chromosome. Proc Natl Acad Sci USA. (2007) 104:14872-7. doi: 10.1073/pnas.0702356104

15. Su C, Khan A, Zhou P, Majumdar D, Ajzenberg D, Darde M-L, et al. Globally diverse Toxoplasma gondii isolates comprise six major clades originating from a small number of distinct ancestral lineages. Proc Natl Acad Sci USA. (2012) 109:5844-9. doi: 10.1073/pnas.1203190109 
16. Ragozo AM, Pena HFJ, Yai LEO, Su C, Gennari SM. Genetic diversity among Toxoplasma gondii isolates of small ruminants from Brazil: novel genotypes revealed. Vet Parasitol. (2010) 170:307-12. doi: 10.1016/j.vetpar.2010.02.024

17. Dubey JP, Lago EG, Gennari SM, Su C, Jones JL. Toxoplasmosis in humans and animals in Brazil: high prevalence, high burden of disease, and epidemiology. Parasitology. (2012) 139:1375-424. doi: 10.1017/S0031182012000765

18. da Silva Ramos T, de Jesus Pena HF, dos Santos Junior AG, de Faria Santos LMJ, Cademartori BG, Oliveira S, et al. Characterization of Toxoplasma gondii isolates from herds of sheep in southern Brazil reveals the archetypal type II genotype and new non-archetypal genotypes. Parasitol Int. (2018) 67:59-63. doi: 10.1016/j.parint.2017.03.004

19. Katzer F, Canton G, Burrells A, Palarea-Albaladejo J, Horton B, Bartley PM, et al. Immunization of lambs with the S48 strain of Toxoplasma gondii reduces tissue cyst burden following oral challenge with a complete strain of the parasite. Vet Parasitol. (2014) 205:46-56. doi: 10.1016/j.vetpar.2014. 07.003

20. Pena HFJ, Soares RM, Amaku M, Dubey JP, Gennari SM. Toxoplasma gondii infection in cats from São Paulo state, Brazil: seroprevalence, oocyst shedding, isolation in mice, and biologic and molecular characterization. Res Vet Sci. (2006) 81:58-67. doi: 10.1016/j.rvsc.2005. 09.007

21. Pena HFJ, Gennari SM, Dubey JP, Su C. Population structure and mousevirulence of Toxoplasma gondii in Brazil. Int J Parasitol. (2008) 38:561-9. doi: 10.1016/j.ijpara.2007.09.004

22. Chiebao DP, Pena HFDJ, Cabral AD, Rocca MP, Lopes EG, Valadas SYOB, et al. Infection of mice with oocysts of Toxoplasma gondii by oral route showed differences of virulence from Brazilian RFLP genotypes BrI and BrIII. Res Vet Sci. (2016) 107:257-60. doi: 10.1016/j.rvsc.2016.06.010

23. Ogassawara $S$, Benassi $S$. Infecção experimental de gatos com coração de bovino parasitado por Sarcocystis sp. Arq do Inst Biol. (1980) 47:27-32.

24. Fleisch A, Werne S, Heckendorn F, Hartnack S, Piechotta M, Bollwein $\mathrm{H}$, et al. Comparison of 6-day progestagen treatment with Chronogest ?? $\mathrm{CR}$ and Eazi-breed??? CIDR ?? G intravaginal inserts for estrus synchronization in cyclic ewes. Small Rumin Res. (2012) 107:141-6. doi: 10.1016/j.smallrumres.2012.05.014

25. Buxton D. Ovine toxoplasmosis: a review. J R Soc Med. (1990) 83:509-11. doi: $10.1177 / 014107689008300813$

26. Camargo ME. Introdução às técnicas de imunofluorescência. Rev Bras Patol Clín. (1974) 10:143-69.

27. Dubey JP, Hattel AL, Lindsay DS, Topper MJ. Neonatal Neospora caninum infection in dogs: isolation of the causative agent and experimental transmission. J Am Vet Med Assoc. (1988) 193:1259-63.

28. Alton GG, Maw J, Rogerson BA, McPherson GG. The serological diagnosis of bovine brucellosis: an evaluation of the complement fixation, serum agglutination and rose bengal tests. Aust Vet J. (1975) 51:57-63. doi: 10.1111/j.1751-0813.1975.tb09404.x

29. Faine S, Adler B, Bolin C, Perolat P. Leptospira and Leptospirosis, 2nd ed. Melbourne, VIC: MediSci (1999). p.272.

30. Prophet EB. Laboratory Methods in Histotechnology. Washington, DC: Amer Registry of Pathology (1992). 279 p.

31. Atmaca HTK, Gazyagci AN, Canpolat S, Kul OU. Hepatic stellate cells increase in Toxoplasma gondii infection in mice. Parasit Vectors. (2013) 6:135. doi: 10.1186/1756-3305-6-135

32. Dubey JP. Refinement of pepsin digestion method for isolation of Toxoplasma gondii from infected tissues. Vet Parasitol. (1998) 74:75-7. doi: 10.1016/S0304-4017(97)00135-0

33. Burg JL, Grover CM, Pouletty P, Boothroyd JC. Direct and sensitive detection of a pathogenic Toxoplasma gondii by polymerase chain reaction. J Clin Microbiol. (1989) 27:1787-92.

34. Ausubel FM, Brent R, Kingston RE, Moore DD, Seidman JG, Smith JA, et al. Short Protocols in Molecular Biology, 4th ed. New York, NY: Wiley (1999). $1104 \mathrm{p}$.

35. Soares RM, Lopes EG, Keid LB, Sercundes MK, Martins J, Richtzenhain LJ. Identification of Hammondia heydorni oocysts by a heminestedPCR (hnPCR-AP10) based on the H. heydorni RAPD fragment AP10. Vet Parasitol. (2011) 175:168-72. doi: 10.1016/j.vetpar.2010. 09.022
36. Su C, Zhang X, Dubey JP. Genotyping of Toxoplasma gondii by multilocus PCR-RFLP markers: a high resolution and simple method for identification of parasites. Int J Parasitol. (2006) 36:841-8. doi: 10.1016/j.ijpara.2006. 03.003

37. da Motta AC, Vieira MIB, Bondan C, Edelweiss MI, Dametto MA, Gomes $\hat{A}$. Ovine abortion associated with toxoplasmosis: serological, anatomopathological and immuno-histochemistry characterization. Brazilian J Vet Parasitol. (2008) 17:204-8.

38. Edwards JF, Dubey JP. Toxoplasma gondii abortion storm in sheep on a Texas farm and isolation of mouse virulent atypical genotype $T$. gondii from an aborted lamb from a chronically infected ewe. Vet Parasitol. (2013) 192:129-36. doi: 10.1016/j.vetpar.2012.09.037

39. Williams RH, Morley EK, Hughes JM, Duncanson P, Terry RS, Smith JE, et al. High levels of congenital transmission of Toxoplasma gondii in longitudinal and cross-sectional studies on sheep farms provides evidence of vertical transmission in ovine hosts. Parasitology. (2005) 130:301-7. doi: $10.1017 /$ S0031182004006614

40. Morley EK, Williams RH, Hughes JM, Terry RS, Duncanson P, Smith JE, et al. Significant familial differences inthe frequency of abortion and Toxoplasma gondii infection within a flock of Charollais sheep. Parasitology. (2005) 131:181-5. doi: 10.1017/S0031182005007614

41. Rodger SM, Maley SW, Wright SE, Mackellar A, Wesley F, Sales J, et al. Role of endogenous transplacental transmission in toxoplasmosis in sheep. Vet Rec. (2006) 159:768-72. doi: 10.1136/vr.159.23.768

42. Lopes FMR, Gonçalves DD, dos Reis CR, Breganó RM, Freire RL, de Freitas JC, et al. Presence of domesticated cats and visual impairment associated to Toxoplasma gondii serum positive children at an elementary school in Jataizinho, state of Paraná, Brazil. Rev Bras Parasitol Vet. (2009) 17:12-5. doi: 10.1590/S1984-29612008000100003

43. Vasconcelos-Santos DV, Machado Azevedo DO, Campos WR, Oréfice F, Queiroz-Andrade GM, Carellos ÉVM, et al. Congenital toxoplasmosis in southeastern Brazil: results of early ophthalmologic examination of a large cohort of neonates. Ophthalmology. (2009) 116:2199-2205. doi: 10.1016/j.ophtha.2009.04.042

44. Herrmann DC, Maksimov P, Hotop A, Groß U, Däubener W, Liesenfeld $\mathrm{O}$, et al. Genotyping of samples from German patients with ocular, cerebral and systemic toxoplasmosis reveals a predominance of Toxoplasma gondii type II. Int J Med Microbiol. (2014) 304:911-6. doi: 10.1016/j.ijmm.2014. 06.008

45. Mendes NHD, Oliveira CBS, Garcia CA, Holanda CMXC, Andrade-Neto VF. Epidemiological and serological profiles of ocular toxoplasmosis in the municipality of Natal, northeastern Brazil. Trans R Soc Trop Med Hyg. (2014) 108:656-61. doi: 10.1093/trstmh/tru113

46. Franco PS, da Silva NM, de Barbosa BF, de Gomes AO, Ietta F, Shwab EK, et al. Calomys callosus chronically infected by Toxoplasma gondii clonal type II strain and reinfected by Brazilian strains is not able to prevent vertical transmission. Front Microbiol. (2015) 6:1-13. doi: 10.3389/fmicb.2015. 00181

47. Abreu Moreira-Souza AC, Rangel TP, Batista da Silva SR, Figliuolo VR, Baggio Savio LE, Schmitz F, et al. Disruption of Purinergic Receptor P2X7 signaling increases susceptibility to cerebral toxoplasmosis. Am J Pathol. (2019). 189:730-38. doi: 10.1016/j.ajpath.2019.01.001

48. Fernandez C, Jaimes J, Ortiz MC, Ramirez JD. Host and Toxoplasma gondii genetic and non-genetic factors influencing the development of ocular toxoplasmosis: a sistematic review. Infect Genet Evol. (2016) 44:199-209. doi: 10.1016/j.meegid.2016.06.053

49. Franco M, Panas MW, Marino ND, Lee MC, Buchholz KR, Kelly FD, et al. A novel secreted Protein, MYR1, is central to Toxoplasma's manipulation of host cells. mBio. (2016) 7:e02231-15. doi: 10.1128/mBio.02 231-15

50. da Cunha IA, Zulpo DL, Bogado AL, de Barros LD, Taroda A, Igarashi M, et al. Humoral and cellular immune responses in pigs immunized intranasally with crude rhoptry proteins of Toxoplasma gondii plus Quil-A. Vet Parasitol. (2012) 186:216-21. doi: 10.1016/j.vetpar.2011.11.034

51. Ajzenberg D, Cogné N, Paris L, Bessières $\mathrm{M}-\mathrm{H}$, Thulliez P, Filisetti D, et al. Genotype of 86 Toxoplasma gondii isolates associated with human congenital toxoplasmosis, and correlation with clinical findings. J Infect Dis. (2002) 186:684-9. doi: $10.1086 / 342663$ 
52. Gilbert RE, Freeman K, Lago EG, Bahia-Oliveira LMG, Tan HK, Wallon $\mathrm{M}$, et al. Ocular sequelae of congenital toxoplasmosis in Brazil compared with Europe. PLoS Negl Trop Dis. (2008) 2:8-14. doi: 10.1371/journal.pntd. 0000277

53. Wastling JM, Harkins D, Maley S, Innes E, Panton W, Thomson K, et al. Kinetics of the local and systemic antibody response to primary and secondary infection with S48 Toxoplasma gondii in sheep. J Comp Pathol. (1995) 112:5362. doi: 10.1016/S0021-9975(05)80089-1

54. Castaño P, Fuertes $M$, Regidor-Cerrillo J, Ferre I, Fernández $M$, Ferreras MC, et al. Experimental ovine toxoplasmosis: Influence of the gestational stage on the clinical course, lesion development and parasite distribution. Vet Res. BioMed Central. (2016) 47:1-14. doi: 10.1186/s13567016-0327-z

55. Costa JGL, Tavares AT, Silva DRC, Pinto LV, Baraviera RCA, Noviello MLM, et al. Kinetics of parasite distribution after reinfection with genetically distinct strains of Toxoplasma gondii. Exp Parasitol. (2018) 184:22-30. doi: 10.1016/j.exppara.2017.11.003

Conflict of Interest Statement: The authors declare that the research was conducted in the absence of any commercial or financial relationships that could be construed as a potential conflict of interest.

Copyright (® 2019 Chiebao, Pena, Passarelli, Santín, Pulz, Strefezzi, Sevá, Martins, Lopes, Grisi Filho, Gennari and Soares. This is an open-access article distributed under the terms of the Creative Commons Attribution License (CC BY). The use, distribution or reproduction in other forums is permitted, provided the original author(s) and the copyright owner(s) are credited and that the original publication in this journal is cited, in accordance with accepted academic practice. No use, distribution or reproduction is permitted which does not comply with these terms. 